\title{
STRATEGI PENINGKATAN LAYANAN KANTOR POS BANDUNG 40000
}

\author{
Somadi $^{1}$, Angelita Claudia Sitinjak ${ }^{2}$ \\ Program Studi D4 Logistik Bisnis, Politeknik Pos Indonesia \\ ${ }^{1)}$ Somadi@poltekpos.ac.id \\ 2) angelitaclaudia2410@gmail.com
}

\begin{abstract}
ABSTRAK
Kantor Pos Bandung 40000 merupakan perusahaan yang bergerak di bidang layanan pos dan memiliki bagian pelayanan yang berhubungan langsung dengan customer memberikan pelayanan yang baik. Namun, dalam aktivitasnya di bagian pelayanan terjadi beberapa masalah terkait dengan kualitas pelayanannya seperti perubahan nama penerima western union, nomor barcode tidak naik data, terganggunya jaringan sistem untuk mengakses situs web ( $u r l)$, dan pembatalan transaksi karena barcode tidak ada. Penelitian ini bertujuan untuk mengetahui masalah yang paling dominan, faktor penyebab dan langkah-langkah yang harus dilakukan untuk meminimalisir terjadinya masalah tersebut. Metode yang digunakan dalam penelitian ini adalah DMAIC. Adapun teknik analisis yang digunakan yaitu diagram SIPOC, Checksheet, Diagram Pareto, Identifikasi CTQ, fishbone diagram, Analisis $5 \mathrm{~W}+1 \mathrm{H}$. Berdasarkan hasil penelitian, bahwa masalah yang sering terjadi yaitu perubahan nama penerima western union, nomor barcode tidak naik data, dan terganggunya jaringan sistem untuk mengakses situs web (url). Adapun faktor yang menyebabkan permasalahan tersebut yaitu karyawan yang kurang fokus dan terliti, kurangnya pemeliharaan material dan jaringan. Strategi untuk meminimalisir permasalahan tersebut adalah pelatihan dan family ghatering, pengecekan material secara berkala, pemberian nomor antrian kepada customer, pengawasan terhadap karyawan yang bekerja, pemeliharaan dan pengadaan jaringan internet.
\end{abstract}

\section{Kata Kunci: barcode, penerima layanan, jaringan, strategi perusahaan, DMAIC}

\section{PENDAHULUAN}

Suatu perusahaan jasa dalam aktivitasnya menjadi hal wajib untuk mengelola jasa dengan baik, sehingga secara prinsip memerlukan manajemen profesional pada pemasaran, operasi maupun sumber daya manusia. Integrasi unsur-unsur tersebut akan menjadi kunci keberhasilan perusahaan jasa untuk meningkatkan performansi. Hal ini seakan-akan menyiratkan bahwa setiap perusahaan harus mampu memberikan kualitas layanan jasa yang baik dimana kualitas pelayanan dimulai dari kebutuhan pelanggan dan berakhir dengan kepuasan (Nilasari \& Istiatin, 2015). Kualitas pelayanan merupakan titik awal dalam merebut pangsa pasar sehingga tingkat kepuasan tidak hanya perlu dipertahankan tetapi juga harus ditingkatkan dimana dalam melayani masyarakat, semakin baik pelayanan yang diberikan oleh pemberi pelayanan maka kepuasan pelanggan akan semakin meningkat.

Kepuasan pelanggan atau konsumen adalah hal pokok yang tidak boleh diabaikan, dimana kepuasan konsumen merupakan aspek strategis dalam memenangkan persaingan dan mempertahankan citra perusahaan di masyarakat yang luas. Kepuasan konsumen atas pelayanan yang diberikan oleh perusahaan akan diketahui apabila melakukan suatu pengukuran dan pengujian terhadap konsumen dimana pelayanan dinilai memuaskan apabila pelayanan tersebut dapat memenuhi kebutuhan dan harapan konsumen (Hadiyati, 2010). Dengan demikian, memahami kebutuhan dan harapan konsumen adalah dasar bagi suksesnya pemasaran karena dengan demikian perusahaan dapat menyusun strategi yang efektif untuk mendukung penawaran yang menarik bagi pasar sasaran (Nilasari \& Istiatin, 2015).

Saat ini persaingan dunia usaha semakin ketat, termasuk persaingan bisnis dan layanan jasa. Salah satu perusahaan jasa yang dikenal telah lama berkecimpung dalam bisnis dan layanan pengiriman adalah Kantor Pos Bandung 40000. Kantor Pos Bandung 40000 merupakan sebuah Badan Usaha Milik Negara (BUMN). Kantor Pos Bandung 40000 merupakan salah satu industri jasa yang banyak dipakai oleh berbagai lapisan masyarakat sehingga harus benar-benar memperhatikan keinginan dan harapan pelanggan, kepuasan maupun ketidakpuasan pelanggan.

Kantor Pos Bandung 40000 memiliki beberapa bagian salah satunya adalah bagian pelayanan. Bagian pelayanan merupakan divisi atau bagian yang bertanggung jawab untuk data kiriman dan memberikan layanan yang berhubungan langsung dengan customer. 
Pada saat melayani konsumen, Kantor Pos Bandung 40000 mengalami berbagai permasalahan terhadap layanan yang diberikan seperti perubahan nama penerima western union, nomor barcode tidak naik data, terganggunya jaringan sistem untuk mengakses situs web (url) dan pembatalan transaksi karena barcode tidak ada.

Dengan adanya masalah tersebut, maka akan menghambat kelancaran transaksi dan menimbulkan laporan pengaduan yang diterima oleh Kantor Pos Bandung 40000. Sehingga hal tersebut akan mengancam kelangsungan hidup perusahaan dimana masyarakat tidak lagi mempercayakan Kantor Pos Bandung 40000 sebagai layanan yang baik untuk mengirimkan barangnya. Selain kehilangan kepercayaan pelanggan, tentu juga dapat merusak image atau citra dari perusahaan.

Dengan demikian, untuk mengatasi masalah tersebut, maka Kantor Pos Bandung 40000 perlu memperbaiki kualitas pelayanannya kepada pelanggan guna mempertahankan agar pelanggan tetap menggunakan jasa Kantor Pos Bandung 40000. Menurut Somadi \& Karwan (2020), perusahaan harus tetap menjaga kualitas pelayanannya kepada konsumen agar konsumen merasa puas guna menjaga loyalitas konsumen

Oleh sebab itu diperlukannya metode yang tepat untuk mendapatkan solusi yang terbaik dalam mengatasi permasalahan yang ada di perusahaan sehingga perusahaan mampu menjaga kualitas pelayanannya. Metode yang dapat digunakan untuk mengatasi masalah tersebut salah satunya menggunakan metode DMAIC. Metode DMAIC terdiri dari define, measure, analyze, improve, dan control yang bertujuan untuk menemukan masalah yang paling dominan, kemudian menganalisis serta menemukan solusi yang tepat untuk meminimalisir kesalahan. Hal ini dilakukan semata-mata untuk menjaga kualitas pelayanan yang diberikan oleh perusahaan. Menurut Somadi et al., (2020), perusahaan jasa pengiriman harus memperhatikan kualitas pelayanan yang diberikan kepada konsumen. Hal ini disebabkan karena kualitas pelayanan merupakan salah satu upaya dari perusahaan dalam membangun kerjasama dengan konsumen.

Dengan demikian, perumusan strategi pelayanan tepat sangat diperlukan dalam menjaga kualitas pelayanan kepada customer. Hal tersebut dilakukan karena mengingat pentingnya kualitas layanan yang dihasilkan perusahaan karena mempengaruhi tingkat kepuasan konsumen. Apabila kinerja pelayanan dan lainnya dibawah harapan maka pelanggan akan tidak puas yang berakibat pelanggan akan mencari produk yang lain bahkan menjatuhkan citra perusahaan. Sebaliknya, apabila kinerja sesuai harapan maka pelanggan akan merasa puas. Pelanggan yang puas akan setia lebih lama, kurang sensitif terhadap harga dan memberi komentar yang baik tentang perusahaan tersebut (Maulana, 2016).

\section{METODE PENELITIAN}

Penelitian berlokasi di Kantor Pos Bandung 40000. Jenis data yang digunakan berasal dari data primer dan data sekunder, dengan teknik pengumpulan data yang digunakan yakni studi dokumentasi, observasi dan wawancara. Pengambilan data di Kantor Pos Bandung 40000 dilakukan dari bulan Agustus 2020 hingga November 2020. Penelitian ini menggunakan pendekatan kuantitatif dengan metode analisis yaitu DMAIC dengan singkatan define, measure, analyze, improve, dan control. Metode ini digunakan untuk memperbaiki permasalahan yang muncul dalam bisnis. Metode DMAIC adalah sebuah siklus improvement yang berbasis kepada data (performance data), yang digunakan untuk meningkatkan, mengoptimasi dan menstabilkan proses bisnis pada suatu perusahaan.

Metode DMAIC dimulai dari tahapan define atau penentuan permasalahan yang akan dijadikan landasan perbaikan. Selanjutnya measure, yaitu melakukan pengukuraan yang diperlukan sebagai landaasan usulan perbaikan yang akan dijalankan. Kemudian analyze atau melakukan analisis atas hasil pengukuran, improve merumuskan langkah-langkah perbikan yang perlu dilakukan dan control atau tindakan pengawasan atas pelaksanaan perbaikan yang dilakukan. Berikut penjelasan dari metode DMAIC tersebut.

1. Define

Menurut Somadi (2020), define merupakan tahap identifikasi awal guna melihat permasalahan terjadi pada perusahaan. Tahap define dilakukan dengan cara pembuatan diagram SIPOC dan indentifikasi masalah.

a. Diagram SIPOC. Pembuatan diagram SIPOC ini berasal dari lima elemen yang ada pada diagram yaitu supplier, input, process, output, dan customer yang dilakukan untuk menunjukkan segala aktivitas yang terjadi pada bagian pelayanan di Kantor Pos Bandung 40000.

b. Identifikasi Masalah. Menurut Hartanto (2010) mengatakan bahwa, identifikasi permasalahan merupakan tahapan yang dilakukan untuk mengenai situasi sistem nyata yang ada serta untuk menemukan permasalahan- permasalahan yang terjadi dan mungkin dapat diangkat untuk kerja praktek.

\section{Measure}

Pada tahap measure fokus pada pemahaman kinerja proses yang dipilih untuk diperbaiki, pengumpulan data yang akan dianalisis, dan penilaian sistem pengukuran untuk memastikan validitas pengukuran dan kapabilitas proses yang diteliti. Pengukuran yang baik dapat dilihat dari indikator seperti spesifik, terukur, bisa dicapai, realistis, dan ada rentang/jangka waktu. Dalam menganalisis measure menggunakan checksheet, diagram pareto dan identifikasi Critical to Quality (CTQ).

a. Checksheet. Menurut Hartanto (2010), checksheet adalah alat bantu yang memiliki bentuk dan isi lembar pengumpulan data (checklist) untuk mempermudah proses pengumpulan data dan analisis, serta untuk mengetahui area permasalahan berdasarkan frekuensi dari jenis atau 
penyebab dan mengambil keputusan untuk melakukan perbaikan atau tidak

b. Diagram Pareto. Diagram pareto bertujuan untuk memperjelas faktor yang paling penting atau yang paling besar dari beberapa faktor yang ada dengan menemukan permasalahan yang paling penting untuk segera diselesaikan (ranking tertinggi) sampai dengan masalah yang tidak harus segera diselesaikan (ranking terendah). Perhitungannya adalah seperti uraian dibawah ini :

$\%$ Permasalahan $=\frac{\text { jumlah masing } \text {-masing permasalahan }}{\text { jumlah permasalahan keseluruhan }} \times 100 \%$

c. Identifikasi Critical to Quality (CTQ). Adapun langkah-langkah dalam $C T Q$ ini adalah:

- Menghitung Critical To Quality (CTQ)

Pada tahap ini yaitu menentukan kriteria yang menimbulkan atau memiliki potensial untuk menimbulkan kegagalan atau kecacatan.

- Menetapkan karakteristik Critical To Quality (CTQ)

Pada tahap $C T Q$ ini menetapkan permasalahan dan jenis kerugiannya.

\section{Analyze}

Menurut Somadi (2020), Analyze adalah tahap yang berfungsi untuk menggali informasi akar masalah terhadap permasalahan yang terpilih dari analisis sebelumnya. Tahap analyze digunakan untuk mencari penyebab terjadinya kerusakan dengan menggunakan teknik analisis fishbone. Analisis diagram fishbone atau diagram tulang ikan juga dapat digunakan untuk menganalisa penyebab permasalahan kerusakan barang kiriman yang terjadi.

\section{Improve}

Menurut Sumarna \& Kemala (2015), tahap improve merupakan rencana tindakan untuk melaksanakan peningkatan kualitas dengan six sigma. Setelah mengetahui penyebab kejadian, maka penulis memberikan usulan-usulan perbaikan dari masalah yang terjadi. Berdasarkan uraian pembahasan masalah dan penyebab akar masalah mengenai permasalahan pada bagian pelayanan, penulis menggunakan metode $5 \mathrm{~W}+$ $1 \mathrm{H}$ (what, when, why, where, who, how) terhadap analisis akar masalah tersebut. $5 \mathrm{~W}+1 \mathrm{H}$ membutuhkan pertanyaan yang benar dan akurat, sehingga akan memperoleh permasalahan yang lengkap dan solusi yang tepat.

Adapun tahapan-tahapan dalam menggunakan analisis $5 \mathrm{~W}+1 \mathrm{H}$ sebagai berikut:

1) What, bermakna apa permasalahan yang akan dilakukan perbaikan?

2) Why, bermakna kenapa perlu dilakukan perbaikan?

3) Where, bermakna dimana lokasi perbaikan akan dilakukan?

4) When, bermakna kapan perbaikan akan dilakukan?

5) Who, bermakna siapa yang bertanggungjawab terhadap perbaikan yang akan dilakukan?

6) How, bermakna bagaimana strategi untuk mengatasi permasalahan yang akan dilakukan perbaikan?

5. Control

Menurut Sumarna \& Kemala (2015), dalam tahap control dilakukan standarisasi apabila usulan perbaikan dilaksanakan dan mencapai keberhasilan. Teknik analisis pada tahap ini akan digunakan SOP yang dibuat ditujukan kepada seluruh orang-orang yang terlibat, terutama kepada bagian pelayanan yang berhubungan langsung kepada cutomer sehingga bisa meminimalisir terjadinya kesalahan.

\section{HASIL DAN PEMBAHASAN}

Berdasarkan data yang diperoleh dari hasil pengumpulan data, maka dilakukan berbagai pengolahan dan analisis data. Berikut ini adalah hasil dan pembahasan terkait hasil pengolahan data yang telah dilakukan.

1. Define

Tahap define merupakan tahap untuk mengidentifikasi masalah dalam penelitian. Masalah yang dijelaskan dalam penelitian ini terkait dengan masalah kualitas pelayanan yang terjadi di Kantor Pos Bandung 40000. Berikut ini hasil analisis pada tahap define:

a. SIPOC Diagram

Diagram SIPOC digunakan untuk menyajikan tampilan "sekilas" dari aliran kerja. Diagram SIPOC ini berasal dari lima elemen yang ada pada diagram yaitu supplier, input, process, output, dan customer. Berikut ini diagram SIPOC Kantor Pos Bandung 40000 :

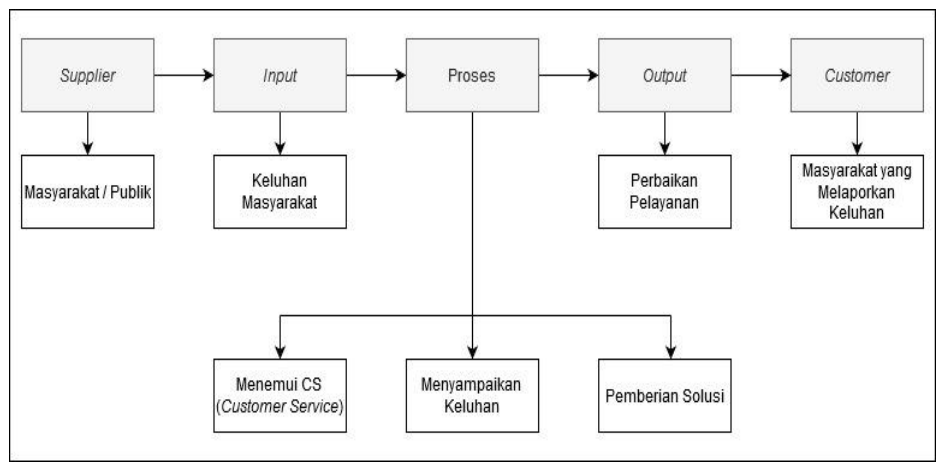

Gambar 1. Diagram SIPOC

Sumber: Hasil Analisis Data, Tahun 2021

Berdasarkan gambar di atas dapat dijelaskan sebagai berikut:

1. Supplier

Supplier adalah orang atau kelompok yang memberikan informasi kunci, bahan-bahan atau sumber daya lainnya kepada proses. Kantor Pos Bandung 40000 melakukan pengadaan yang dibutuhkan untuk berlangsungnya proses bisnis jasa pengiriman barang dengan berhubungan langsung dengan masyarakat atau masyarakat (publik) lah yang menjadi supplier Kantor Pos Bandung 40000.

2. Input

Input merupakan sesuatu yang diberikan oleh supplier. Pada bagian pelayanan, keluhan masyarakat lah yang menjadi input dalam proses bisnis pengiriman barang.

3. Proses

Proses adalah sekumpulan langkah yang mengubah dan idealnya menambah nilai input. Dimana proses yang 
dilakukan Kantor Pos Bandung 40000 dimulai dari supplier atau masyarakat menemui CS (customer service) atau Asman (asisten manager) pelayanan MLO dan mengatakan keluhannyaa. Kemudian customer service ataupun asman pelayanan MLO memberikan solusi atau jalan keluar dari keluhan tersebut.

4. Output

Output adalah produk atau proses final. Output yang dihasilkan adalah perbaikan pelayanan atau solusi.

5. Customer

Customer adalah orang atau kelompok atau proses yang menerima output, dimana customer dari Kantor Pos Bandung 40000 adalah masyarakat yang melaporkan keluhan.

b. Identifikasi Masalah

Berikut ini terdapat 4 permasalahan yang terjadi di bagian pelayanan di Kantor Pos Bandung 40000 yaitu:

1. Perubahan nama penerima Western Union

Western Union atau yang biasa disebut WU adalah layanan pengiriman dan penerimaan uang yang memberikan solusi terhadap kecepatan, ketepatan dan keamanan kiriman uang untuk luar negeri (International). Sebelum mengirim Western Union, maka harus memastikan bahwa nama lengkap yang akan menerima wesel tersebut sudah benar sesuai dengan kartu identitas, baik itu KTP, SIM dan sejenisnya. Namun tetap saja masih terjadi kesalahan dalam penulisan nama. Kesalahan penulisan nama terjadi karena saat penginputan data berasal dari formulir yang diisi oleh customer. Jika terjadi kesalahan dalam penulisan nama di wesel pos, maka hal itu dapat dikatakan sebagai masalah bagi perusahaan karena jika terjadi kesalahan nama, maka penerima tidak akan bisa mencairkan uangnya. Hal tersebut akan menimbulkan keluhan dan dapat mengurangi kepuasan customer. Sehingga ketika ada kesalahan nama penerima, customer melakukan perubahan nama namun hal tersebut bisa mempersulit penerima dalam mencairkan wesel dan bisa juga tidak bisa diterima. Berikut ini data perubahan nama di bulan Agustus - November 2020.

Tabel 1. Data Perubahan Nama Penerima Western Union

\begin{tabular}{|c|c|c|c|}
\hline No. & Tanggal & Alasan & No. MTCN \\
\hline 1. & $\begin{array}{c}04 \text { Agustus } \\
2020\end{array}$ & $\begin{array}{l}\text { Salah nama depan (first } \\
\text { name) }\end{array}$ & $956-922-7525$ \\
\hline 2. & $\begin{array}{c}07 \text { Agustus } \\
2020\end{array}$ & $\begin{array}{l}\text { Salah nama depan (first } \\
\text { name) dan nama belakang } \\
\text { (last name) }\end{array}$ & $606-978-6738$ \\
\hline 3. & $\begin{array}{l}11 \text { Agustus } \\
2020\end{array}$ & $\begin{array}{l}\text { Salah nama negara } \\
\text { (country) }\end{array}$ & $568-744-1730$ \\
\hline 4. & $\begin{array}{c}15 \text { Agustus } \\
2020\end{array}$ & $\begin{array}{l}\text { Salah nama negara } \\
\text { (country) }\end{array}$ & $360-827-1946$ \\
\hline 5. & $\begin{array}{c}28 \text { Agustus } \\
2020\end{array}$ & $\begin{array}{l}\text { Salah nama belakang (last } \\
\text { name) }\end{array}$ & $304-686-4202$ \\
\hline 6. & $\begin{array}{c}2 \text { September } \\
2020 \\
\end{array}$ & $\begin{array}{l}\text { Salah nama negara } \\
\text { (country) }\end{array}$ & $740-813-9890$ \\
\hline 7. & $\begin{array}{c}14 \text { September } \\
2020\end{array}$ & $\begin{array}{l}\text { Salah nama depan (first } \\
\text { name) dan nama belakang } \\
\text { (last name) }\end{array}$ & $955-776-6110$ \\
\hline 8. & $\begin{array}{c}23 \text { September } \\
2020\end{array}$ & $\begin{array}{l}\text { Salah nama depan (first } \\
\text { name) }\end{array}$ & $533-865-8980$ \\
\hline 9. & $\begin{array}{c}30 \text { September } \\
2020\end{array}$ & $\begin{array}{l}\text { Salah nama depan (first } \\
\text { name) dan nama belakang } \\
\text { (last name) }\end{array}$ & $521-899-9706$ \\
\hline
\end{tabular}

\begin{tabular}{|c|c|l|c|}
\hline 10. & $\begin{array}{c}\text { 03 Oktober } \\
2020\end{array}$ & $\begin{array}{l}\text { Salah nama depan (first } \\
\text { name) }\end{array}$ & 591-957-1000 \\
\hline 11. & $\begin{array}{c}\text { November } \\
2020\end{array}$ & $\begin{array}{l}\text { Salah nama depan (first } \\
\text { name) dan nama belakang } \\
\text { (last name) }\end{array}$ & 339-842-1023 \\
\hline
\end{tabular}

Sumber: Kantor Pos Bandung 40000, Tahun 2020

Dari Tabel 1 dapat diketahui bahwa jumlah kejadian perubahan nama penerima western union terjadi sebanyak 11 kali, dimana pada bulan Agustus terjadi sebanyak 5 kali, bulan September sebanyak 4 kali dan bulan Oktober sampai November masing-masing terjadi 1 kali.

2. Nomor barcode tidak naik data

Barcode atau kode batang adalah suatu kumpulan data optik yang dibaca mesin. Barcode ini digunakan untuk mengotomatiskan sistem pemeriksaan di swalayan dan penggunaannya telah menyebar ke berbagai kegunaan lain sebagai Auto ID Data Capture. Setelah melewati proses pengiriman dari petugas loket, maka barang kiriman tersebut akan dibawa ke manifest untuk discan barcode ulang untuk pengecekan dan pendataan manifest serah terima item. Pada beberapa kejadian ada barcode yang sudah di scan, namun barcode tersebut tidak muncul di layar monitor. Untuk itu, petugas manifest akan segera melaporkan nomor barcode tersebut untuk segera ditanggulangi. Ada beberapa alasan mengapa nomor barcode tidak naik data yaitu situs web ( $u r l)$ yang diakses error atau pun human error dimana petugas kurang teliti dalam melihat barcode yang sudah di scan dan muncul di layar monitor dan kabel scanner yang rusak sehingga tidak connect ke PC. Berikut ini adalah data barcode tidak naik data dari bulan Agustus - November 2020.

Tabel 2. Barcode Tidak Naik Data

\begin{tabular}{|c|l|c|l|}
\hline No. & Tanggal & Barcode & \multicolumn{1}{|c|}{ Keterangan } \\
\hline \multirow{2}{*}{1.} & $\begin{array}{l}05 \text { Agustus } \\
2020\end{array}$ & 17924986486 & \multirow{2}{*}{$\begin{array}{l}\text { Situs Web (URL) manifest } \\
\text { error }\end{array}$} \\
\cline { 2 - 3 } 2. & $\begin{array}{l}\text { 05 Agustus } \\
2020\end{array}$ & 17924986506 & $\begin{array}{l}\text { Situs Web (URL) manifest } \\
\text { error }\end{array}$ \\
\hline 3. & $\begin{array}{l}08 \text { Agustus } \\
2020\end{array}$ & 17924921614 & $\begin{array}{l}\text { Bagian manifest kurang teliti } \\
\text { memperhatikan barcode } \\
\text { yang sudah di data }\end{array}$ \\
\hline 4. & $\begin{array}{l}\text { 21 } \\
\text { September } \\
2020\end{array}$ & 18107101784 & $\begin{array}{l}\text { Bagian manifest kurang teliti } \\
\text { memperhatikan barcode } \\
\text { yang sudah di data }\end{array}$ \\
\hline
\end{tabular}

umber: Kantor Pos Bandung 40000, Tahun 2020

Dari Tabel 2 dapat diketahui bahwa kejadian nomor barcode tidak naik data hanya terjadi pada bulan Agustus dan September, dimana pada bulan Agustus terjadi sebanyak 3 kali dan di bulan September terjadi 1 kali.

3. Terganggunya jaringan sistem untuk mengakses situs web (url)

Jaringan komputer ialah suatu sistem yang terdiri atas sebuah komputer yang didesain untuk bisa berbagi sumber daya. Masalah terakhir pada situs web (url) terjadi dikarenakan adanya suatu sistem yang gagal akses yang disebabkan oleh jaringan yang terganggu akibat pemakaian jaringan terlalu banyak, sehingga membuat proses kerja terhambat dimulai dari data entry, cetak reminttace RS-3R dan RS-4R, entry PosPay menjadi terhambat. Masalah yang kedua terjadi dikarenakan pemblokiran internet lain untuk menjaga 
keamanan data dan hanya menggunakan satu provider saja yang menyebabkan kecepatan akses menjadi lambat. Masalah terganggunya jaringan ini terjadi sebanyak 3 kali dengan rincian terjadi pada bulan Oktober sebanyak 1 kali dan pada bulan November terjadi sebanyak 2 kali.

4. Pembatalan transaksi karena barcode tidak ada

Barcode atau kode batang yang dapat dibaca oleh pemindai optik yang disebut pembaca kode batang atau dipindai dari sebuah gambar oleh perangkat lunak khusus. Barcode akan discan bersamaan dengan pencetakan resi karena di resi terdapat nomor barcode. Namun ada beberapa kejadian dimana petugas loket kurang memperhatikan barcode yang dia punya, sehingga ketika melakukan transaksi dan tanpa disadari barcodenya tidak ada maka transaksi akan dibatalkan.

Tabel 3. Data Pembatalan Transaksi Karena

Barcode Tidak Ada

\begin{tabular}{|c|c|c|c|c|}
\hline No. & Tanggal & Produk & Barcode & BSU \\
\hline \multirow{7}{*}{1.} & \multirow{7}{*}{$\begin{array}{l}11 \\
\text { November } \\
2020\end{array}$} & \multirow{7}{*}{$\begin{array}{l}\text { Surat Kilat } \\
\text { Khusus } \\
\text { (SKH) }\end{array}$} & 18136570017 & 10.000 \\
\hline & & & 18136570020 & 7.000 \\
\hline & & & 18136570033 & 7.000 \\
\hline & & & 18136570046 & 11.000 \\
\hline & & & 18136570059 & 7.000 \\
\hline & & & 18136570062 & 12.000 \\
\hline & & & 18136570075 & 22.000 \\
\hline \multirow{7}{*}{2.} & \multirow{7}{*}{$\begin{array}{l}27 \\
\text { November } \\
2020\end{array}$} & \multirow{7}{*}{$\begin{array}{l}\text { Surat Kilat } \\
\text { Khusus } \\
\text { (SKH) }\end{array}$} & 18173230012 & 12.000 \\
\hline & & & 18173230025 & 12.000 \\
\hline & & & 18173230038 & 12.000 \\
\hline & & & 18173230041 & 12.000 \\
\hline & & & 18173230054 & 12.000 \\
\hline & & & 18173230067 & 12.000 \\
\hline & & & 18173230070 & 12.000 \\
\hline
\end{tabular}

Sumber: Kantor Pos Bandung 40000, Tahun 2020

Dari Tabel 3 dapat diketahui bahwa kejadian pembatalan transaksi karena barcode tidak ada, hanya terjadi pada bulan November yaitu sebanyak 2 kali.

\section{Measure}

\section{a. Checksheet}

Tujuan digunakannya checksheet ini adalah untuk mempermudah proses pengumpulan data dan analisis, serta untuk mengetahui area permasalahan berdasarkan frekuensi dari jenis atau penyebab dan mengambil keputusan untuk melakukan perbaikan atau tidak. Berikut adalah frekuensi terjadinya setiap masalah yang terjadi di Kantor Pos Bandung 40000 :

Tabel 4. Data Check Sheet

\begin{tabular}{|l|l|l|l|l|l|}
\hline \multicolumn{1}{|c|}{ Kejadian } & Agst & Sept & Okt & Nov & Total \\
\hline $\begin{array}{l}\text { Perubahan nama } \\
\text { penerima } \\
\text { Western Union }\end{array}$ & IX & IIII & I & I & 11 \\
\hline $\begin{array}{l}\text { Nomor barcode } \\
\text { tidak naik data }\end{array}$ & III & I & & & 4 \\
\hline $\begin{array}{l}\text { Terganggunya } \\
\text { jaringan system } \\
\text { untuk mengakses } \\
\text { situs web (url) }\end{array}$ & & I & II & 3 \\
\hline $\begin{array}{l}\text { Pembatalan } \\
\text { transaksi karena } \\
\text { barcode tidak ada }\end{array}$ & & & & II & 2 \\
\hline \multicolumn{7}{|c|}{ Total } & 8 & 5 & 2 & 5 & 20 \\
\hline
\end{tabular}

Dari data check sheet diatas, dapat disimpulkan, bahwa permasalahan yang paling sering terjadi adalah perubahan nama penerima Western Union.
Permasalahan tersebut memiliki frekuensi tertinggi yaitu mencapai 11 kali terjadi dalam waktu 4 bulan. Sedangkan permasalahan yang memiliki frekuensi terendah atau paling jarang terjadi adalah pembatalan transaksi karena barcode tidak ada dimana permasalahan tersebut memiliki frekuensi sebesar 2 kali.

\section{b. Diagram Pareto}

Diagram pareto adalah grafik batang yang menunjukkan masalah berdasarkan urutan banyaknya kejadian yang mengelola kesalahan, masalah atau cacat untuk membantu memusatkan perhatian pada usaha penyelesaian masalah dan dapat membantu menemukan permasalahan yang paling penting untuk segera diselesaikan (ranking tertinggi) sampai dengan masalah yang tidak harus segera diselesaikan (ranking terendah). Perhitungannya adalah seperti uraian dibawah ini :

$\%$ Permasalahan $=\frac{\text { jumlah masing-masing permasalahan }}{\text { jumlah permasalahan } \text { eseluruhan }} \times 100 \%$

Persentase setiap permasalahan :

1. Perubahan nama penerima western union

$$
\begin{aligned}
& \% \text { Permasalahan }=\frac{11}{20} \times 100 \% \\
& \% \text { Permasalahan }=55 \%
\end{aligned}
$$

2. Nomor barcode tidak naik data

$$
\begin{aligned}
\% \text { Permasalahan } & =\frac{4}{20} \times 100 \% \\
\% \text { Permasalahan } & =20 \%
\end{aligned}
$$

3. Terganggunya jaringan system untuk mengakses situs web (url)

$\%$ Permasalahan $=\frac{3}{20} \times 100 \%$

$\%$ Permasalahan $=15 \%$

4. Pembatalan transaksi karena barcode tidak ada

$\%$ Permasalahan $=\frac{2}{20} \times 100 \%$

$\%$ Permasalahan $=10 \%$

Berikut adalah tabel persentase dan diagram pareto dari setiap frekuensi:

Tabel 5. Data Persentase dari Setiap Frekuensi

\begin{tabular}{|l|c|c|c|c|}
\hline Kejadian & Frekuensi & $\begin{array}{l}\text { Akumulasi } \\
\text { Frekuensi }\end{array}$ & $\begin{array}{c}\text { Persentase } \\
\text { dari Total }\end{array}$ & $\begin{array}{c}\text { Akumulasi } \\
\text { Persentase }\end{array}$ \\
\hline $\begin{array}{l}\text { Perubahan } \\
\text { nama penerima } \\
\text { Western Union }\end{array}$ & 11 & 11 & $55 \%$ & $55 \%$ \\
\hline $\begin{array}{l}\text { Nomor barcode } \\
\text { tidak naik data }\end{array}$ & 4 & 15 & $20 \%$ & $75 \%$ \\
\hline $\begin{array}{l}\text { Terganggunya } \\
\text { jaringan system } \\
\text { untuk } \\
\text { mengakses } \\
\text { situs web (url) }\end{array}$ & 3 & 18 & $15 \%$ & $90 \%$ \\
\hline $\begin{array}{l}\text { Pembatalan } \\
\text { transaksi } \\
\text { karena barcode } \\
\text { tidak ada }\end{array}$ & 2 & 20 & $10 \%$ & $100 \%$ \\
\hline Total & 20 & & $100 \%$ & \\
\hline
\end{tabular}

Sumber: Hasil Pengolahan Data, Tahun 202

Berikut merupakan hasil diagram pareto dari keempat permasalahan tersebut sebagai berikut: 


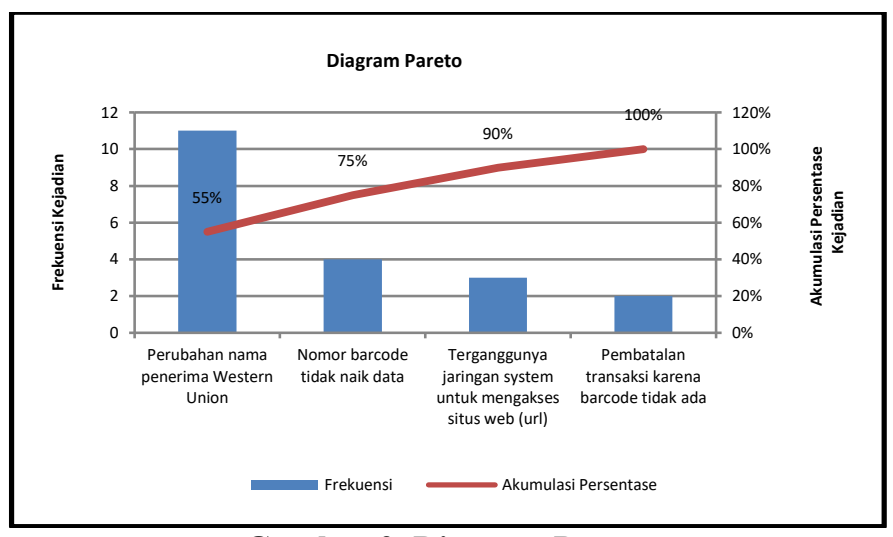

Gambar 2. Diagram Pareto

Sumber: Hasil Pengolahan Data, Tahun 2021

Dari tabel persentase dan diagram pareto diatas dapat disimpulkan bahwa yang menjadi permasalahan yang paling sering terjadi adalah perubahan nama penerima Western Union dimana tingkat terjadinya mencapai $55 \%$. Masalah yang sering terjadi selanjutnya adalah nomor barcode tidak naik data yaitu mencapai $20 \%$ dan selanjutnya $15 \%$ yaitu terganggunya jaringan system untuk mengakses situs web (url). Kemudian masalah yang paling jarang terjadi diantara empat masalah lainnya adalah pembatalan transaksi karena barcode tidak ada yang tingkat terjadinya hanya $10 \%$.

c. Identifikasi Critical to Quality (CTQ)

Perhitungan $C T Q$ pada tahap ini dilakukan dengan menggunakan checksheet. Checksheet dapat dilihat pada Tabel 4 dan berdasarkan checksheet tersebut akan dilakukan perhitungan untuk mengetahui persentase kumulatif dan akan memperoleh tabel frekuensi. Berikut adalah tabel persentase Critical to Quality (CTQ) dari jumlah permasalahan.

Tabel 6. Persentase CTQ dari Jumlah

Permasalahan

\begin{tabular}{|c|l|c|c|c|c|}
\hline No. & Kejadian & Frekuensi & $\begin{array}{c}\text { Akumulasi } \\
\text { Frekuensi }\end{array}$ & $\begin{array}{c}\text { Persentase } \\
\text { dari Total }\end{array}$ & $\begin{array}{c}\text { Akumulasi } \\
\text { Persentase }\end{array}$ \\
\hline 1. & $\begin{array}{l}\text { Perubahan } \\
\text { nama } \\
\text { penerima } \\
\text { Western } \\
\text { Union }\end{array}$ & 11 & 11 & $55 \%$ & $55 \%$ \\
\hline 3. & $\begin{array}{l}\text { Nomor } \\
\text { barcode } \\
\text { tidak naik } \\
\text { data }\end{array}$ & 4 & 15 & $20 \%$ & $75 \%$ \\
\hline $\begin{array}{l}\text { Terganggu } \\
\text { nya } \\
\text { jaringan } \\
\text { sistem } \\
\text { untuk } \\
\text { mengakses } \\
\text { situs web } \\
\text { (url) }\end{array}$ & 3 & 18 & $15 \%$ & $90 \%$ \\
\hline 4. & $\begin{array}{l}\text { Pembatala } \\
\text { n transaksi } \\
\text { karena } \\
\text { barcode } \\
\text { tidak ada }\end{array}$ & 2 & 20 & $10 \%$ & $100 \%$ \\
\hline Total & 20 & & $100 \%$ & \\
\hline
\end{tabular}

Sumber: Hasil Pengolahan Data, Tahun 2021

Untuk melakukan identifikasi CTQ yang dikembangkan melalui spesifikasi yang bersumber dari checksheet dan standar spesifikasi yang ada di perusahaan

Tabel 7. Karakteristik CTQ

\begin{tabular}{|c|l|l|}
\hline No. & \multicolumn{1}{|c|}{ CTQ } & \multicolumn{1}{c|}{ Jenis Kerugian } \\
\hline 1. & $\begin{array}{l}\text { Perubahan nama } \\
\text { penerima western } \\
\text { union }\end{array}$ & $\begin{array}{l}\text { - Tidak bisa melakukan pencairan } \\
\text { uang oleh penerima } \\
\text { Adanya keluhan dan berpengaruh } \\
\text { besar terhadap kepercayaan dari } \\
\text { konsumen }\end{array}$ \\
\hline 2. & $\begin{array}{l}\text { Nomor barcode } \\
\text { tidak naik data }\end{array}$ & Tidak bisa melakukan pengiriman \\
\hline 3. & $\begin{array}{l}\text { Terganggunya } \\
\text { jaringan sistem } \\
\text { untuk mengakses } \\
\text { situs web (url) }\end{array}$ & $\begin{array}{l}\text { Penginputan data terhambat } \\
\text { Proses transaksi akan terhambat }\end{array}$ \\
\hline 4. & $\begin{array}{l}\text { Pembatalan } \\
\text { transaksi karena } \\
\text { barcode tidak ada }\end{array}$ & $\begin{array}{l}\text { Berpengaruh besar terhdap } \\
\text { kepercayaan dari konsumen }\end{array}$ \\
\hline
\end{tabular}

Sumber: Hasil Pengolahan Data, Tahun 2021

Berdasarkan tabel diatas dapat diketahui kerugian yang akan timbul akibat adanya masalah yaitu; perubahan nama penerima western union, nomor barcode tidak naik data, terganggunya jaringan sistem untuk mengakses situs web ( $u r l)$ dan pembatalan transaksi karena barcode tidak ada. Persentase kesalahan terbesar yang dominan terjadi pada bagian pelayanan di Kantor Pos Bandung 40000 adalah perubahan nama penrima western union sebesar 55\%. Oleh karena itu, penulis lebih difokuskan kepada permasalahan perubahan nama penerima western union.

\section{Analyze}

Pada tahap analisis dilakukan menggunakan diagram fishbone untuk mengetahui akar permasalahan. Fishbone diagram digunakan untuk mencari akar penyebab permasalahan yang terjadi baik penyebab utama maupun akar masalah dari penyebab utama tersebut.

Adapun masalah yang terjadi di Kantor Pos Bandung 40000 bagian pelayanan yaitu; (1) perubahan nama penerima western union, (2) nomor barcode tidak naik data, (3) terganggunya jaringan sistem untuk mengakses situs web ( $u r l)$ dan (4) pembatalan transaksi karena barcode tidak ada. Namun, dalam analisis diagram fishbone ini penulis memfokuskan untuk permasalahan perubahan nama penerima western union, nomor barcode tidak ada dan terganggunya jaringan sistem untuk mengakses situs web (url).

Berikut adalah analisa akar dari permasalahan perubahan nama penerima western union dengan menggunakan fishbone diagram. 


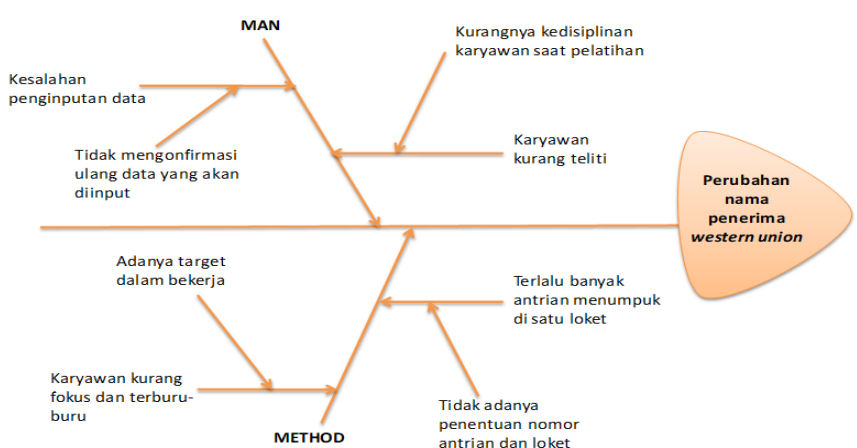

Gambar 3. Diagram Fishbone Perubahan Nama Penerima Western Union

Sumber: Hasil Pengolahan Data, Tahun 2021

Diagram fishbone diatas menjelaskan beberapa faktor yang menyebabkan terjadinya perubahan nama penerima western union di Kantor Pos Bandung 40000. Perubahan nama penerima western union disebabkan oleh 2 faktor yaitu man dan method. Permasalahan man karena karyawan kurang teliti dalam melakukan pekerjaannya yaitu penginputan data dari form pengiriman western union yang telah diisi oleh pengirim. Ketidaktelitian yang dilakukan karyawan karena karyawan kurang disiplin saat pelatihan. Kemudian penyebab kedua dari faktor man karena karyawan tidak mengonfirmasi ulang data yang akan di input sehingga terjadi kesalahan penginputan data. Kesalahan ini juga terjadi ketika proses penginputan data dari form pengiriman western union yang telah diisi oleh pengirim. Sementara itu untuk faktor method disebabkan karena tidak adanya penentuan nomor antrian dan loket dimana customer dengan sesuka hati memilih loket kiriman dan menyebabkan terlalu banyak antrian menumpuk di satu loket tertentu. Kemudian penyebab kedua dari faktor method karena adanya target dalam bekerja yang dapat menambah penghasilan membuat karyawan kurang fokus dan terburu-buru dalam bekerja.

Berdasarkan penelitian yang dilakukan oleh Mintarsih (2015), bahwa faktor penyebab terjadinya salah penginputan data karena karyawan yang tidak teliti dalam melakukan pekerjaannya yang masih dilakukan dengan manual sehingga menyebabkan ketidaktelitian. Hasil penelitian ini juga senada dengan penelitian yang dilakukan oleh Puspitasari, bahwa penyebab terjadi kesalahan dalam penginputan data disebabkan oleh kurangnya ketelitian dalam menjalankan tugasnya yaitu dalam menngisi atau menginput data pada Surat Setoran Pajak (Puspitasari, 2019).

Berikut adalah analisa akar dari permasalahan nomor barcode tidak naik data dengan menggunakan fishbone diagram.

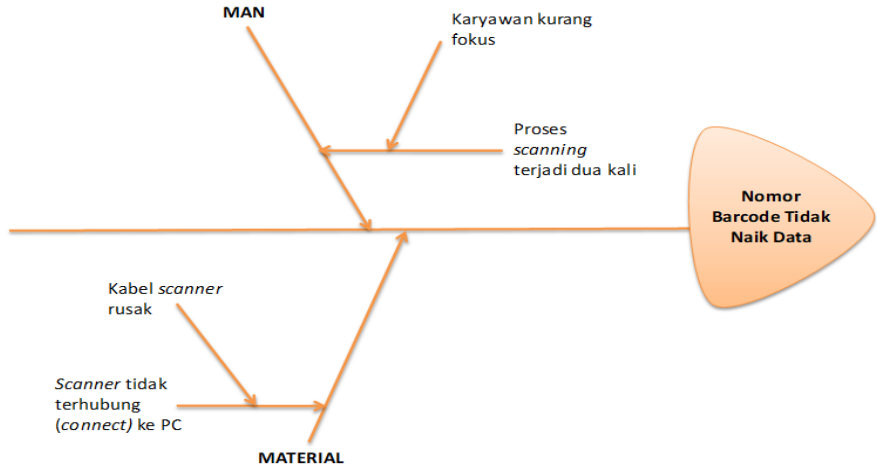

Gambar 4. Diagram Fishbone Nomor Barcode Tidak Naik Data

Sumber: Hasil Pengolahan Data, Tahun 2021

Diagram fishbone di atas menjelaskan beberapa faktor yang menyebabkan terjadinya nomor barcode tidak naik data di Kantor Pos Bandung 40000. Nomor barcode tidak naik data disebabkan oleh 2 faktor yaitu man dan material. Permasalahan man karena karyawan kurang fokus dalam melakukan pekerjaannya yaitu melakukan proses scanning barcode pada resi kiriman sehingga menyebabkan proses scanning terjadi dua kali. Sementara itu untuk faktor material disebabkan scanner yang merupakan alat untuk memindai suatu bentuk, dokumen, gelombang dan lainnya atau dengan kata lain disebut scan tidak terhubung (connect) ke PC dikarenakan kabel scannernya rusak.

Berdasarkan penelitian yang dilakukan oleh Akbar et al. (2017), bahwa faktor penyebab terjadinya nomor barcode tidak naik data karena banyaknya scan yang dilakukan dimana response time pada saat scanner membaca barcode dan menampilkan LCD yang didapatkan response berarti barcode sudah terbaca atau naik data. Hasil penelitian yang lain yang dilakukan oleh Trisnasari (2019) dapat diketahui bahwa penyebab terjadi nomor barcode tidak naik data disebabkan oleh masalah pada kabel scanner dan mengusulkan untuk menggunakan scanner yang terhubung dengan wifi dan tanpa kabel.

Berikut adalah analisa akar dari permasalahan terganggunya jaringan sistem untuk mengakses situs web (url) dengan menggunakan fishbone diagram.

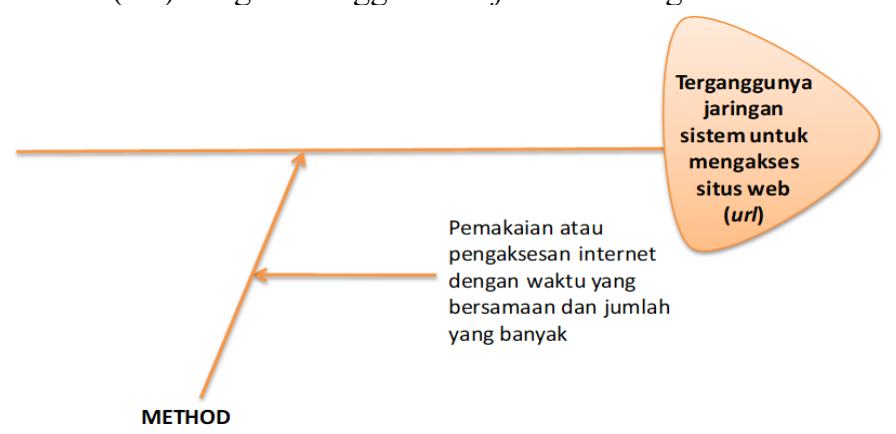

Gambar 5. Diagram Fishbone Terganggunya Jaringan Sistem Untuk Mengakses Situs web (url) Sumber: Hasil Pengolahan Data, Tahun 2021

Diagram fishbone di atas menjelaskan faktor yang menyebabkan terjadinya terganggunya jaringan sistem untuk mengakses situs web ( $u r l$ ) di Kantor Pos Bandung 40000. Terganggunya jaringan sistem untuk mengakses 
situs web (url) hanya disebabkan oleh 1 faktor saja yaitu method. Permasalahan method karena pemakaian atau pengaksesan internet dengan waktu yang bersamaan dan jumlah yang banyak. Hal itu akan berpengaruh kepada kecepatan akses jaringan dan menyebabkan jaringan sistem akan terganggu.

Berdasarkan penelitian yang dilakukan oleh Nopaprilia \& Ahdika (2018), bahwa faktor penyebab terjadinya terganggunya jaringan sistem untuk mengakses situs web (url) karena kecepatan akses internet akan jadi lambat karena tidak sebanding dengan pengguna dan menyebabkan jaringan terganggu. Hasil penelitian ini juga senada dengan penelitian yang dilakukan oleh Hidayat \& Rahmatulloh (2015), bahwa penyebab terjadi terganggunya jaringan sistem untuk mengakses situs web (url) disebabkan oleh pengaksesan dalam jumlah yang banyak dimana kegiatan akademik di Universitas Siliwangi berbassi web menjadi menurun atau terganggu akibat banyaknya user yang menggunakan sistem.

\section{Improve}

Berdasarkan uraian pembahasan masalah dan penyebab akar masalah mengenai permasalahan pada bagian pelayanan, maka tahap selanjutnya yaitu melakukan analisis $5 \mathrm{~W}+1 \mathrm{H}$ (what, when, why, where, who, how) terhadap analisis akar masalah tersebut. $5 \mathrm{~W}$ $+1 \mathrm{H}$ membutuhkan pertanyaan yang benar dan akurat, sehingga akan memperoleh permasalahan yang lengkap dan solusi yang tepat. Analisis ini digunakan bertujuan untuk mencari strategi untuk meminimalisir permasalahan yang ada di Kantor Pos Bandung 40000.

Berikut ini adalah hasil analisis $5 \mathrm{~W}+1 \mathrm{H}$ terkait permasalahan perubahan nama penerima western union:

Tabel 8. Analisis $5 \mathrm{~W}+\mathbf{1 H}$ Perubahan Nama Penerima Western Union

\begin{tabular}{|c|c|c|c|c|}
\hline No & Faktor & $\begin{array}{c}\text { Penyebab } \\
\text { Utama }\end{array}$ & Uraian & Penjelasan \\
\hline \multirow[t]{6}{*}{1.} & \multirow[t]{6}{*}{ Man } & \multirow{6}{*}{$\begin{array}{l}\text { Kurangnya } \\
\text { kedisiplinan } \\
\text { karyawan saat } \\
\text { pelatihan }\end{array}$} & What & $\begin{array}{l}\text { Karyawan } \\
\text { kurang teliti } \\
\text { dalam bekerja }\end{array}$ \\
\hline & & & When & $\begin{array}{l}\text { Pada saat } \\
\text { petugas loket } \\
\text { melakukan } \\
\text { penginputan } \\
\text { data dari form } \\
\text { pengiriman }\end{array}$ \\
\hline & & & Where & $\begin{array}{l}\text { Loket } \\
\text { pengiriman }\end{array}$ \\
\hline & & & Why & $\begin{array}{l}\text { Agar karyawan } \\
\text { dapat bekerja } \\
\text { dengan teliti } \\
\text { sehingga dapat } \\
\text { meningkatkan } \\
\text { standar kerja } \\
\text { karyawan dan } \\
\text { mecegah } \\
\text { terjadinya } \\
\text { kesalahan }\end{array}$ \\
\hline & & & Who & $\begin{array}{l}\text { Petugas loket } \\
\text { dan karyawan } \\
\text { bagian } \\
\text { pelayanan }\end{array}$ \\
\hline & & & How & $\begin{array}{l}\text { Melakukan } \\
\text { pelatihan } \\
\text { tambahan dan }\end{array}$ \\
\hline
\end{tabular}

\begin{tabular}{|c|c|c|c|c|}
\hline \multirow[t]{2}{*}{ No } & \multirow[t]{2}{*}{ Faktor } & \multirow[t]{2}{*}{$\begin{array}{c}\text { Penyebab } \\
\text { Utama }\end{array}$} & \multirow[t]{2}{*}{ Uraian } & \multirow[b]{2}{*}{\begin{tabular}{l}
\multicolumn{1}{c}{ Penjelasan } \\
family \\
gathering \\
untuk \\
menambah \\
semangat, \\
ketelitian, \\
fokus, \\
kekompakan \\
dan kerja same \\
dalam bekerja \\
serta \\
melakukan \\
pengawsan \\
dalam bekerja.
\end{tabular}} \\
\hline & & & & \\
\hline & & $\begin{array}{l}\text { Tidak } \\
\text { mengonfirmasi } \\
\text { ulang data yang }\end{array}$ & What & $\begin{array}{l}\text { Kesalahan } \\
\text { penginputan } \\
\text { data }\end{array}$ \\
\hline & & akan di input & When & $\begin{array}{l}\text { Pada saat } \\
\text { petugas loket } \\
\text { melakukan } \\
\text { penginputan } \\
\text { data dari form } \\
\text { pengiriman }\end{array}$ \\
\hline & & & Where & $\begin{array}{l}\text { Loket } \\
\text { pengiriman }\end{array}$ \\
\hline & & & Why & $\begin{array}{l}\text { Untuk } \\
\text { mencegah } \\
\text { kesalahan } \\
\text { dalam } \\
\text { penginput data }\end{array}$ \\
\hline & & & Who & $\begin{array}{l}\text { Petugas loket } \\
\text { dan karyawan } \\
\text { bagian } \\
\text { pelayanan }\end{array}$ \\
\hline & & & How & $\begin{array}{l}\text { Atasan dapat } \\
\text { melakukan } \\
\text { pegawasan } \\
\text { langsung } \\
\text { terhadap } \\
\text { karyawan yang } \\
\text { sedang bekerja } \\
\text { dan melakukan } \\
\text { pelatihan } \\
\text { tambahan } \\
\text { kepada } \\
\text { karyawan. } \\
\end{array}$ \\
\hline 2. & Method & $\begin{array}{l}\text { Tidak adanya } \\
\text { penentuan } \\
\text { nomor antrian } \\
\text { dan nomor loket }\end{array}$ & What & $\begin{array}{l}\text { Terlalu banyak } \\
\text { antrian } \\
\text { menumpuk } \\
\text { dalam satu } \\
\text { loket tertentu }\end{array}$ \\
\hline & & & When & $\begin{array}{l}\text { Perbaikan perlu } \\
\text { dilakukan } \\
\text { sebelum } \\
\text { customer } \\
\text { memasuki loket } \\
\text { pengiriman }\end{array}$ \\
\hline & & & Where & $\begin{array}{l}\text { Loket } \\
\text { pengiriman }\end{array}$ \\
\hline & & & Why & $\begin{array}{l}\text { Agar } \\
\text { memudahkan } \\
\text { security dalam } \\
\text { mengatur } \\
\text { antrian dan } \\
\text { tidak } \\
\text { mengganggu } \\
\text { fokus petugas } \\
\text { loket }\end{array}$ \\
\hline & & & Who & $\begin{array}{l}\text { Security dan } \\
\text { penanggung } \\
\text { jawab loket } \\
\text { pengiriman }\end{array}$ \\
\hline
\end{tabular}




\begin{tabular}{|c|c|c|c|c|}
\hline \multirow[t]{2}{*}{ No } & Faktor & $\begin{array}{c}\text { Penyebab } \\
\text { Utama }\end{array}$ & Uraian & Penjelasan \\
\hline & & & How & $\begin{array}{l}\text { Melakukan } \\
\text { evaluasi dan } \\
\text { melakukan } \\
\text { penentuan } \\
\text { nomor antrian } \\
\text { dan loket } \\
\text { sebelum masuk } \\
\text { ke loket } \\
\text { pengiriman }\end{array}$ \\
\hline & & \multirow[t]{6}{*}{$\begin{array}{l}\text { Adanya target } \\
\text { dalam bekerja }\end{array}$} & What & $\begin{array}{l}\text { Karyawan } \\
\text { kurang fokus } \\
\text { dalam bekerja }\end{array}$ \\
\hline & & & When & $\begin{array}{l}\text { Pada saat } \\
\text { petugas loket } \\
\text { melakukan } \\
\text { penginputan } \\
\text { data dari form } \\
\text { pengiriman }\end{array}$ \\
\hline & & & Where & $\begin{array}{l}\text { Loket } \\
\text { pengiriman }\end{array}$ \\
\hline & & & Why & $\begin{array}{l}\text { Agar karyawan } \\
\text { bisa lebih fokus } \\
\text { dan tidak } \\
\text { terburu-buru } \\
\text { dalam bekerja } \\
\text { sehingga dapat } \\
\text { meningkatkan } \\
\text { standar kerja } \\
\text { dan mencegah } \\
\text { terjadinya } \\
\text { kesalahan } \\
\text { penginputan } \\
\text { data }\end{array}$ \\
\hline & & & Who & $\begin{array}{l}\text { Petugas loket } \\
\text { dan karyawan } \\
\text { bagian } \\
\text { pelayanan }\end{array}$ \\
\hline & & & How & $\begin{array}{l}\text { Perlu } \\
\text { dilakukannya } \\
\text { evaluasi dan } \\
\text { pelatihan } \\
\text { tambahan } \\
\text { dengan tujuan } \\
\text { karyawan harus } \\
\text { tetap fokus } \\
\text { dalam bekerja } \\
\text { walaupun ada } \\
\text { target yang } \\
\text { dapat } \\
\text { menambah } \\
\text { penghasilan }\end{array}$ \\
\hline
\end{tabular}

Sumber: Hasil Pengolahan Data, Tahun 2021

Berikut ini adalah hasil analisis $5 \mathrm{~W}+1 \mathrm{H}$ terkait permasalahan nomor barcode tidak naik data.

Tabel 9. Analisis 5W+1H Nomor Barcode Tidak Naik Data

\begin{tabular}{|l|l|l|l|l|}
\hline No & Faktor & $\begin{array}{l}\text { Penyebab } \\
\text { Utama }\end{array}$ & Uraian & \multicolumn{1}{|c|}{ Penjelasan } \\
\hline 1. & Man & $\begin{array}{l}\text { Kurang } \\
\text { fokusnya } \\
\text { petugas }\end{array}$ & What & $\begin{array}{l}\text { Barcode terscan dua } \\
\text { kali }\end{array}$ \\
\cline { 4 - 6 } & & When & $\begin{array}{l}\text { Pada saat petugas } \\
\text { manifest melakukan } \\
\text { proses scanning pada } \\
\text { barang kiriman }\end{array}$ \\
\cline { 4 - 6 } & & Where & $\begin{array}{l}\text { Manifest serah terima } \\
\text { barang }\end{array}$ \\
\cline { 4 - 6 } & & Why & $\begin{array}{l}\text { Agar karyawan bisa } \\
\text { lebih fokus dalam } \\
\text { bekerja dan menambah } \\
\text { standar kerja karyawan } \\
\text { dan }\end{array}$ \\
& & & $\begin{array}{l}\text { meminimalisir } \\
\text { terjadinya kesalahan }\end{array}$ \\
\hline
\end{tabular}

\begin{tabular}{|c|c|c|c|c|}
\hline No & Faktor & $\begin{array}{l}\text { Penyebab } \\
\text { Utama }\end{array}$ & Uraian & Penjelasan \\
\hline & & & Who & $\begin{array}{l}\text { Petugas manifest dan } \\
\text { karyawan } \\
\text { pelayanan }\end{array}$ \\
\hline & & & How & $\begin{array}{l}\text { Melakukan pelatihan } \\
\text { tambahan untuk } \\
\text { menambah semangat, } \\
\text { ketelitian, fokus, dalam } \\
\text { bekerja. }\end{array}$ \\
\hline \multirow[t]{6}{*}{2.} & \multirow[t]{6}{*}{ Material } & \multirow[t]{6}{*}{$\begin{array}{l}\text { Kabel } \\
\text { scanner } \\
\text { rusak }\end{array}$} & What & $\begin{array}{l}\text { Scanner tidak bisa } \\
\text { terhubung (connect) ke } \\
\mathrm{PC}\end{array}$ \\
\hline & & & When & $\begin{array}{l}\text { Pada saat petugas } \\
\text { manifest melakukan } \\
\text { proses scanning pada } \\
\text { barang kiriman }\end{array}$ \\
\hline & & & Where & $\begin{array}{l}\text { Manifest serah terima } \\
\text { barang }\end{array}$ \\
\hline & & & Why & $\begin{array}{lr}\text { Agar setiap proses dan } \\
\text { transaksi } \\
\text { rangkaian dalam } \\
\text { bisnis perusahaan tidak } \\
\text { mengalami } \\
\begin{array}{l}\text { keterhambatan } \\
\text { kendala }\end{array} \\
\end{array}$ \\
\hline & & & Who & $\begin{array}{l}\text { Bagian model-model } \\
\text { dan bagian pelayanan. }\end{array}$ \\
\hline & & & How & $\begin{array}{l}\text { Melakukan pengecekan } \\
\text { material secara berkala. }\end{array}$ \\
\hline
\end{tabular}

Berikut ini adalah hasil analisis $5 \mathrm{~W}+1 \mathrm{H}$ terkait permasalahan terganggunya jaringan sistem untuk mengakses situ web (url).

Tabel 10. Analisis 5W+1H Terganggunya Jaringan Sistem untuk Mengakses Situs web (url)

\begin{tabular}{|c|c|c|c|c|}
\hline No & Faktor & $\begin{array}{l}\text { Penyebab } \\
\text { Utama }\end{array}$ & Uraian & Penjelasan \\
\hline \multirow[t]{6}{*}{1.} & \multirow[t]{6}{*}{ Method } & \multirow{6}{*}{$\begin{array}{l}\text { Pemakaian } \\
\text { atau } \\
\text { pengaksesan } \\
\text { internet } \\
\text { dengan } \\
\text { waktu yang } \\
\text { bersamaan } \\
\text { dan jumlah } \\
\text { yang banyak }\end{array}$} & What & $\begin{array}{l}\text { Pemakaian atau } \\
\text { pengaksesan internet } \\
\text { dengan waktu yang } \\
\text { bersamaan dan jumlah } \\
\text { yang banyak }\end{array}$ \\
\hline & & & When & $\begin{array}{l}\text { Pada saat penginputan } \\
\text { data }\end{array}$ \\
\hline & & & Where & Bagian pelayanan \\
\hline & & & Why & $\begin{array}{lr}\text { Agar setiap proses dan } \\
\text { transaksi } & \text { dalam } \\
\text { rangkaian } & \text { kegiatan } \\
\text { bisnis perusahaan } \\
\text { tidak mengalami } \\
\text { keterhambatan dan } \\
\text { kendala }\end{array}$ \\
\hline & & & Who & $\begin{array}{l}\text { Bagian IT dan } \\
\text { keseluruhan karyawan }\end{array}$ \\
\hline & & & How & $\begin{array}{l}\text { Melakukan } \\
\text { pemeliharaan jaringan } \\
\text { internet r dan } \\
\text { menambah provider } \\
\text { internet. }\end{array}$ \\
\hline
\end{tabular}

Sumber: Hasil Pengolahan Data, Tahun 2021

\section{Control}

Pada tahap ini akan digunakan Standar Operational Procedure (SOP) yang dibuat untuk ditujukan kepada seluruh orang-orang yang terlibat, terutama kepada bagian pelayanan yang berhubungan langsung kepada cutomer sehingga bisa meminimalisir terjadinya kesalahan. Adapun usulan SOP yang dapat diaplikasikan di Kantor Pos Bandung 40000 adalah 
sebagai berikut

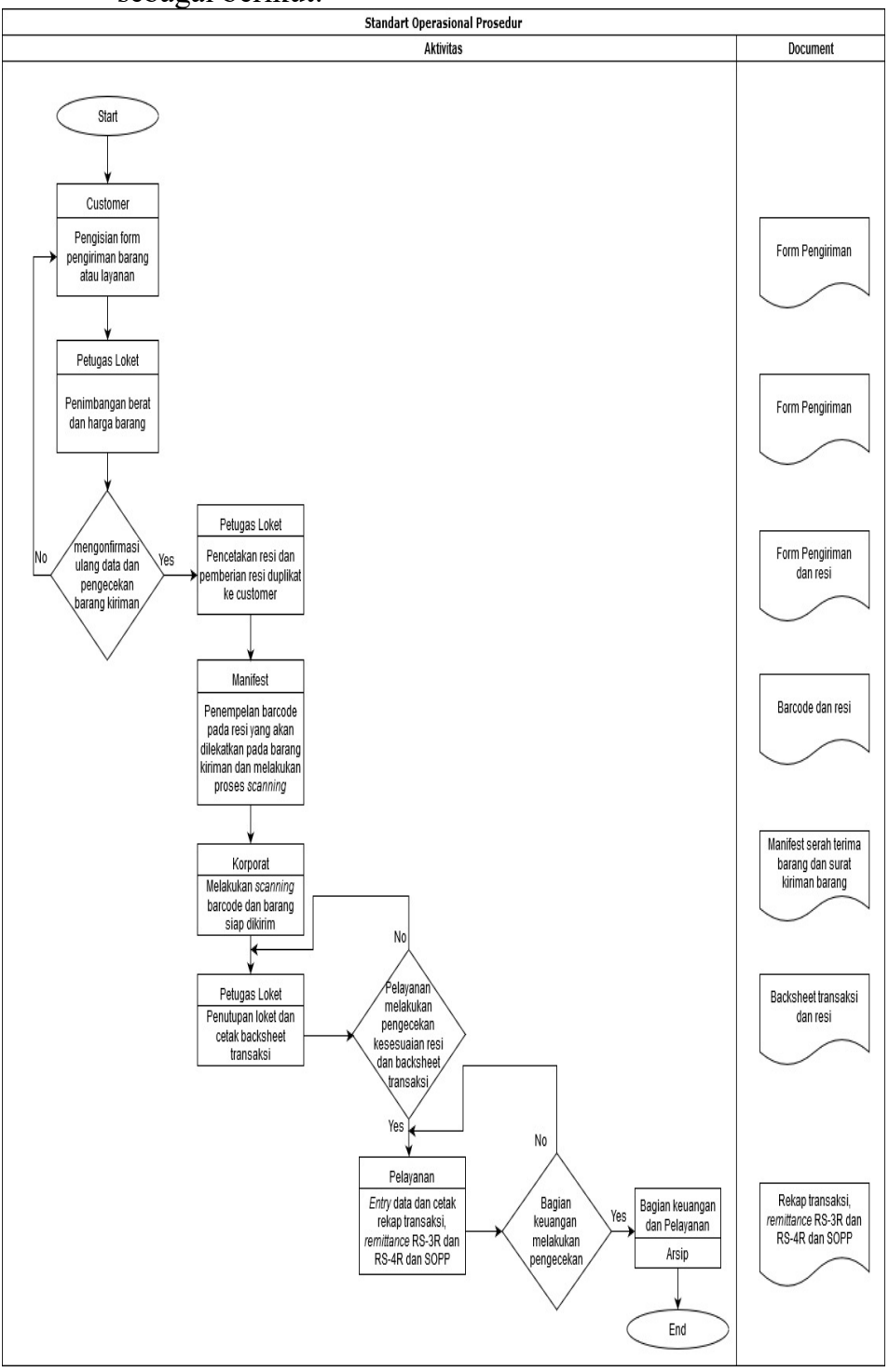

Gambar 6. Standar Operational Procedure

Sumber: Hasil Pengolahan Data, Tahun 2021

\section{Strategi Peningkatan Layanan Kantor Pos Bandung}

Berdasarkan hasil analisis yang telah dilakukan, maka strategi untuk meminimalisir permasalahan perubahan nama penerima western union, nomor barcode tidak naik data, dan terganggunya jaringan sistem untuk mengakses situs web (url) adalah perusahaan dapat melaksanakan pelatihan dan family ghatering, perusahaan dapat melakukan pengecekan material secara berkala, perusahaan memberikan nomor antrian kepada customer, perusahaan melakukan pengawasan terhadap karyawan yang sedang bekerja, perusahaan melakukan pemeliharaan dan pengadaan jaringan internet.

\section{KESIMPULAN}

Berdasarkan hasil analisis yang dilakukan, maka dapat disimpulkan bahwa masalah yang paling dominan adalah perubahan nama penerima western union, nomor barcode tidak naik data dan terganggunya jaringan sistem untuk mengakses situs web $(u r l)$. Adapun faktor yang menyebabkan permasalahan tersebut yaitu karyawan yang kurang fokus dan terliti, kurangnya pemeliharaan material dan jaringan. Strategi untuk meminimalisir permasalahan tersebut, maka perusahaan diharapkan dapat memberikan nomor antrian kepada customer, melakukan pelatihan bagi karyawan, melakukan pengawasan terhadap karyawan, melakukan kegiatan family gathering, melakukan pengecekan material secara berkala, dan memelihara dan pengadaan jaringan internet.

\section{REFERENSI}

[1] Akbar, F., Apriyanto, E., \& Satwiko, A. G. P. (2017). Implementasi Smart Shopping List Menggunakan Barcode Scanner berbasis Komunikasi M2M. E-Proceeding of Engineering, 4(1), 1167-1174.

[2] Hadiyati, E. (2010). Analisis Kualitas Pelayanan dan Pengaruhnya terhadap Loyalitas Nasabah (Studi Kasus pada PT. Pos Indonesia (Persero) Kantor Pos Lawang). Jurnal Manajemen Fakultas Ekonomi Universitas Jambi, 2(2), 81-90.

[3] Hartanto, D. (2010). Analisis Pengendalian Kualitas Kain Selimut Dengan Metode Cause Effect dan Diagram Pareto Pada Departemen Weaving di Perusahaan Kapas Putih. In D3 Manajemen Industri Fakulitas Ekonomi Universitas Sebelas Maret.

[4] Hidayat, E. W., \& Rahmatulloh, A. (2015). Optimasi Server SIMAK Menggunakan Memcached dan Mirror Server Untuk Meningkatkan Kecepatan Akses Layanan Akademik Universitas Siliwangi. S@Cies, 5(2), 69-78.

[5] Maulana, A. S. (2016). Pengaruh Kualitas Pelayanan Dan Harga Terhadap Kepuasan Pelanggan PT. TOI. Jurnal Ekonomi, 7(2), 113125.

[6] Mintarsih, I. (2015). Perancangan Sistem Informasi Penggajian Karyawan Berbasis Objek Pada PT. BE Hear Indonesia. Jurnal Ilmiah Informatika Dan Komputer, 20(1), 17-25.

[7] Nilasari, E., \& Istiatin. (2015). Pengaruh Kualitas Pelayanan Terhadap Kepuasan Konsumen Pada Dealer PT. Ramayana Motor Sukoharjo. Jurnal Paradigma, 13(01), 1-12.

[8] Nopaprilia, K., \& Ahdika, A. (2018). Analisis Antrian Single Channel Server Dengan Layanan Berkelompok Pada Koneksi Internet di Universitas Islam Indonesia. Jurnal Ilmiah Matematika Dan Pendidikan Matematika, 10(1), 53-66.

[9] Puspitasari, A. (2019). Pemindahbukuan Atas Kesalahan Peneytoran dan Pelaporan PPH Final Sudi Pada PT. ABC. In Program Studi Perpajakan Fakultas Ekonomi dan Bisnis Universitas Katolik Soegijapranata.

[10] Somadi, S. (2020). Evaluasi Keterlambatan Pengiriman Barang dengan Menggunakan Metode Six Sigma. Jurnal Logistik Indonesia, 4(2), 81-93.

[11] Somadi, S., \& Karwan, N. J. (2020). Strategi 
Perusahaan Dalam Meminimalisir Terjadinya Selisih Barang Antara Stock on Hand daengan Stock Actual. Competitive, 15(2), 99-104.

[12] Somadi, S., Priambodo, B. S., \& Okarini, P. R. (2020). Evaluasi Kerusakan Barang Dalam Proses Pengiriman Dengan Menggunakan Metode Seven Tools. Jurnal INTECH Teknik Industri Universitas Serang Raya, 6(1), 1-11.

[13] Sumarna, D. L., \& Kemala, E. R. (2015). Analisis Salah Salur Kiriman Surat Kilat Khusus Dengan
Menggunakan Metode Six Sigma (Studi Kasus: PT. POS Indonesia (Persero) Kendal. Jurnal Logistik Bisnis, 5(2), 19-28.

[14] Trisnasari, D. I. (2019). Pengembangan Barcode Reader Untuk Mendukung Komunikasi Tanpa Kabel (WIFI) dengan Menggunakan ARDUINO dan MODUL WIFI ESP8266. Program Studi S1 Teknologi Informasi Fakultas Ilmu Komputer dan Teknologi Informasi Universitas Sumatera Utara. 